\title{
NEUROLEPTANAESTHESIA WITH DIAZEPAM-MORPHINE IN POOR-RISK SURGICAL PATIENTS*
}

\author{
Louis EisenbERG, M.D. AND ALEX M. Kwan, M.D. $\nmid$
}

DiazepaM, a PSychotherapeutic AGENT of the benzodiazepine class, reduces anxiety by a selective depression of the limbic system without causing cortical depression or analgesia. ${ }^{1}$ Relaxation of skeletal muscle is produced by the interruption of spinal interneuronal transmission. Intravenously, minimal changes in cardiovascular function are noted, although transient hypoventilation results, primarily due to a decrease in tidal volume. ${ }^{2}$ No extra-pyramidal side effects, and no effects on the autonomic nervous system have been reported.

Diazepam has been used orally as a hypnotic, intramuscularly for premedication, ${ }^{3,4}$ intravenously for induction of inhalation anaesthesia, ${ }^{5-8}$ and for neuroleptanalgesia. ${ }^{9}$ The supplementation of nitrous oxide-relaxant-hyperventilation technique with diazepam and morphine results in a type of neuroleptanaesthesia that offers excellent analgesia, amnesia, and a high degree of cardiovascular stability.

The present study was undertaken to determine the usefulness of this technique in the anaesthetic management of a specialized group of poor-risk surgical patients. Fifty patients, representing 54 operative procedures, were selected either because of severe preoperative disabilities (Table I), or because of prolonged major surgery (Table II), or both. Seven patients included had interesting anaesthetic problems: halothane hepatitis ( 1 ), methoxyflurane nephropathy (1), awareness during previous anaesthetics (2), agitated alcoholic or schizophrenic states (2), and Parkinsonism, or prolonged L-Dopa therapy (1). The ages ranged from 22-77 years; weights from 44-99 kg; duration of surgery, 100-690 min. Of the total procedures, 48 were elective, 6 were emergency.

\section{METhoD}

\section{Premedication}

One hour prior to surgery, the patients received 5-20 mg diazepam (approximately $0.1 \mathrm{mg} / \mathrm{lb}$ ) combined with $0.4-0.6 \mathrm{mg}$ atropine administered intramuscularly. The substitution of scopolamine $0.4-0.6 \mathrm{mg}$ for the atropine has been reported to potentiate amnesia. ${ }^{10}$ Muscular individuals, in addition, received morphine 8-15 mg. Extremely poor-risk, debilitated patients received only atropine $0.4 \mathrm{mg}$.

\section{Induction}

Anaesthesia was induced with 1-2 $\mathrm{mg}$ morphine followed by $2.5 \mathrm{mg}$ increments of diazepam injected every 30 seconds into a rapidly-running infusion

*Presented in part at Annual Meeting, The Canadian Anaesthetists' Society, 23 June, 1970.

$\nmid$ From the Department of Anesthesiology, Veterans Administration Hospital, Upstate Medical Center, Syracuse, N.Y. 
TABLE I

Associated Medical Conditions

\begin{tabular}{lll}
\hline \hline 1. Cardiovascular & & 9 \\
(a) Old anterior wall infarct & 3 & \\
(b) Congenital heart block & 1 & \\
(c) Acute hemorrhage & 3 & \\
(d) Hypertensive encephalopathy & 1 & \\
(e) Pulmonary embolism & 1 & \\
2. Hepatic & & 15 \\
(a) Jaundice & 5 & \\
(b) Liver cirrhosis & 2 & \\
(c) Chronic alcoholism & 6 & \\
(d) Sclerosing cholangitis & 1 & \\
(e) Post-op liver abscess & 1 & \\
3. Renal & & 2 \\
(a) Methoxyflurane nephropathy & 1 & \\
(b) Nephrectomy (previous) & 1 & \\
4. Endocrine & & 8 \\
(a) Parathyroid adenoma & 1 & \\
(b) Obesity & 3 & \\
(c) Hypersplenism & 1 & \\
(d) Diabetes mellitus & 3 & \\
5. Agitated state & & 2 \\
(a) Schizophrenia & 1 & \\
(b) Chronic alcoholism & 1 & \\
\hline
\end{tabular}

TABLE II

Surgical Procedures Performed

\begin{tabular}{lrr}
\hline 1. Intra-abdominal & \\
(a) Stomach and duodenum & 8 & 30 \\
(b) Biliary tract & 14 & \\
(c) Colon & 6 & \\
(d) Large vessels & 2 & \\
2. Intra-thoracic & & 5 \\
3. Orthopaedic & 3 \\
4. Head and neck & 6 \\
5. Urological & 5 \\
6. Neurosurgical & 5 \\
\hline
\end{tabular}

until drowsiness, loss of eyelid reflex, and pin-point, central pupils ensued. The dose of diazepam required for induction was approximately the same as that given previously for premedication. Nitrous oxide ( $70-75$ per cent) in a total flow of 10 liters/min was administered by face mask with respirations assisted. Following succinylcholine $(60-100 \mathrm{mg})$ and hyperventilation with 100 per cent oxygen for one minute, endotracheal intubation was performed. When risk of aspiration was present, "awake" intubation was performed utilizing a transtracheal block with $2 \mathrm{ml}$ of 1 per cent tetracaine followed by diazepam intravenously.

\section{Maintenance}

Following intubation, nitrous oxide was re-instituted in a lower concentration (50-65 per cent), a long-acting muscle relaxant was injected (d-tubocurare 15-24 $\mathrm{mg}$ ), and moderate hyperventilation was produced with a mechanical ventilator, tidal volume $10-12 \mathrm{ml} / \mathrm{kg}$, rate $10-12 / \mathrm{min}$, with no intermittent sighs. 
Prior to incision, an additional 2-3 $\mathrm{mg}$ morphine were administered as the surgical settling dose. Subsequent increments of morphine (1 mg) were injected when signs of inadequate analgesia appeared (dilatation of pupil, lacrimation, sweating, tachycardia, hypertension); further doses of d-tubocurare (3-6 $\mathrm{mg}$ ) were given to control cough, hiccough, or inadequate relaxation.

\section{Termination}

Curare reversal was routinely accomplished in all patients with atropine 1-1.2 $\mathrm{mg}$ ) and neostigmine $(2-2.5 \mathrm{mg})$, except following prolonged procedures in the elderly or following thoracic surgery, where the endotracheal tube was left in place for postoperative ventilatory support. Following the return of spontaneous respiration, it was occasionally necessary to administer an antagonist (levallorphan $1 \mathrm{mg}$ or nalorphine $5 \mathrm{mg}$ ) to reverse narcotic-induced respiratory depression.

In six patients, arterial blood samples were drawn for blood gas determinations $\left(\mathrm{PaO}_{2}, \mathrm{SaO}_{2}, \mathrm{PaCO}_{2}, \mathrm{pH}\right)$ before and after premedication, following three minutes of 70 per cent nitrous oxide, after one minute of 100 per cent oxygen, hourly during surgery, at the end of surgery, and the first post-operative day.

In each patient blood pressure, pulse rate, electrocardiographic Lead II, rectal tempcrature, urinary output, fluids and blood administered, were measured regularly.

\section{Observations and Results}

\section{Premedication}

The majority of patients arrived in the operating theater awake, calm, and cooperative. Tidal volumes and respiratory rates were adequate, and the patients were able to move onto the operating table themselves. No nausea or vomiting was noted, even though a narcotic was included in the premedication, suggesting a protective anti-emetic action of diazepam. Initial blood pressure and pulse rates were close to preoperative levels.

\section{Induction}

This period was pleasant for the patient, unconsciousness supervening in 2-3 minutes, in a manner quite different from thiopentone. Quiescence, relaxation and tranquility gradually merged into sleep, with no excitement, laryngospasm, coughing, hiccough, hypersecretion, or tachycardia. There was a ready acceptance of the mask, so that assistance to respiration was easily accomplished. With the onset of sleep there was a 10-15 per cent decline in systolic and diastolic pressures associated with a mild bradycardia. Following surgical incision, the blood pressure rose to, or slightly above, control values.

\section{Maintenance}

Cardiovascular stability with a moderate bradycardia persisted throughout surgery. Initially, the supplementary doses of morphine and d-tubocurare were required at 15-20 minute intervals; as surgery progressed, these intervals increased to 45 and 60 minutes. Pupils remained constricted, with dilatation signifying the need for additional analgesia. On the average, $1 \mathrm{mg}$ of morphine was required intravenously every 30 minutes (a 5 -hour major abdominal procedure 
required approximately $10 \mathrm{mg}$ morphine $\mathrm{IV}$ ). The electrocardiogram developed no abnormalities and urine output remained adequate.

\section{Recovery}

Anaesthesia was terminated by discontinuing mechanical ventilation, administering 100 per cent oxygen, and affecting curare reversal; emergence was rapid, so that extubation could be performed shortly. The patients were clear mentally, able to respond to commands, with no restlessness, shivering, nausea, vomiting, dreams, or hallucinations. Analgesia persisted into the postoperative period. A narcotic was usually required for pain relief in 3 to 4 hours. Four of the patients remained drowsy, but rousable, for up to 90 minutes. There were no signs of extrapyramidal excitation.

\section{Amnesia}

It was noteworthy that, despite the premedication with diazepam and morphine, almost all patients recalled their trip to the operating suite, getting onto the operating table, the placement of the blood pressure cuff and the start of the infusion. However, following the intravenous administration of diazepam, a complete loss of memory developed that lasted until the patient awoke in his room; he had no recall of the mask, intubation, extubation or the recovery room. The amnesia did not depend upon the concentration of nitrous oxide used. Whenever an acute episode of blood loss occurred during surgery, nitrous oxide was discontinued, and 100 per cent oxygen was administered. There was never any awareness or recall for these periods postoperatively.

Dundee ${ }^{11}$ has remarked upon the amnesic property of diazepam when given intravenously, and it has been further investigated by Clark. ${ }^{12}$

\section{Blood gases}

The control values were in the normal range (mean $\mathrm{PaO}_{2} 79.4, \mathrm{Paco}_{2} 34.0, \mathrm{SaO}_{2}$ 95.2 per cent, $\mathrm{pH} 7.42$ ). Following premedication, there was a slight decrease in mean $\mathrm{PaO}_{2}$ to 71.4, together with slight rise in mean $\mathrm{Paco}_{2}$ to 36.8 - these changes were not statistically significant. When 70 per cent $\mathrm{N}_{2} \mathrm{O}-30$ per cent $\mathrm{O}_{2}$ was started, the mean $\mathrm{PaO}_{2}$ rose to 114.4 , due to the increase in oxygen concentration, the assistance to ventilation, and the second gas effect for oxygen..$^{13}$ Under controlled mechanical ventilation the mean $\mathrm{PacO}_{2}$ decreased to 28.0, the $\mathrm{pH}$ rose to 7.48 (moderate respiratory alkalosis) while the mean $\mathrm{PaO}_{2}$ decreased to 95.0. The addition of 2 to 3 per cent $\mathrm{CO}_{2}$ to the inhaled mixture resulted in a rise in $\mathrm{PaCO}_{2}$, and a rise in $\mathrm{PaO}_{2}$ to 115.1 (probably due to a rise in cardiac output ${ }^{14}$ ). At the end of surgery, the $\mathrm{PaCO}_{2}$ was in the normal range, while the $\mathrm{PaO}_{2}$ was low, requiring supplemental oxygen in the recovery room (Figure 1).

\section{Complications}

(1) There were four instances of burning sensation following the intravenous injection of diazepam, but no postoperative pain or phlebitis developed. This complication can be prevented by injecting $2.5-\mathrm{mg}$ increments of diazepam into a 


\section{$\mathrm{PaO}_{2}, \mathrm{pH}, \& \mathrm{PaCO}_{2}$ BEFORE, DURING, \& AFTER ANESTHESIA}

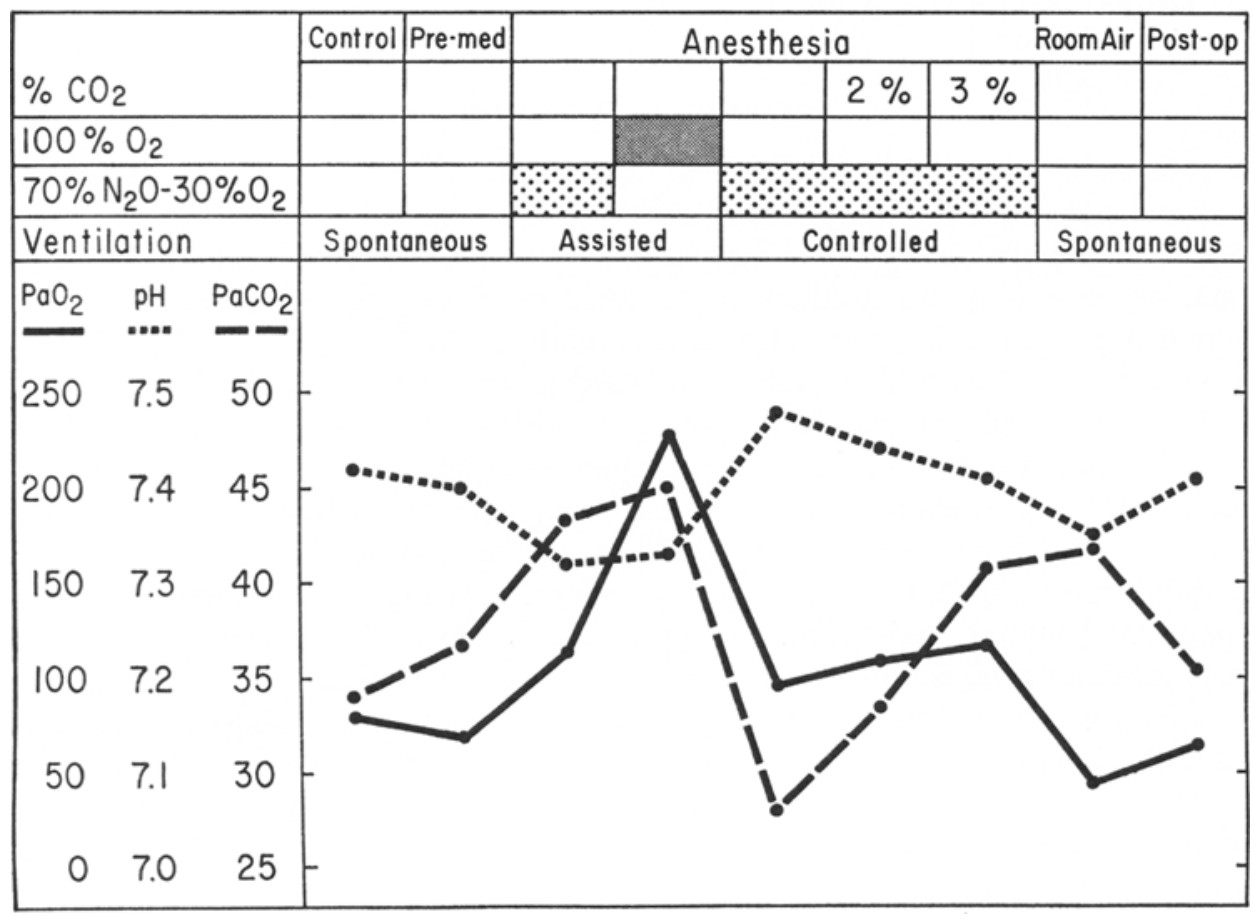

Figure 1

rapidly-rumning infusion, and by using larger veins in the forearm or antecubital fossa as recommended by Wyant. ${ }^{8}$ Knapp $^{7}$ recommends injecting $1 \mathrm{ml}$ of 1 per cent lidocaine into the vein immediately before injecting diazepam, to prevent discomfort.

(2) It became evident that patients taking chlordiazepoxide (Librium ${ }^{\circledR}$ ) for extended periods exhibited a cross-tolerance to diazepam, and required larger amounts intravenously for the induction of sleep (up to $40 \mathrm{mg}$ ).

(3) During exploration of a common bile duct, spasm of the sphincter of Oddi developed following the administration of morphine. It responded to intravenous atropine and did not recur.

(4) There was one case of postoperative respiratory insufficiency. A male patient, age 53 , underwent a $4 / 4$-hour cervical laminectomy $\left(\mathrm{C}_{3}-\mathrm{C}_{6}\right)$ following which he was extubated, only to became cyanotic immediately. There apparently was surgical trauma and oedema in the region of the spinal nerve roots innervating the muscles of the upper chest and diaphragm. Following re-intubation and respiratory assistance for 36 hours, the oedema subsided, muscle tone improved, and the patient could be safely extubated.

(5) There was one death, due to massive tumor emboli to the brain, aortic bifurcation and kidneys, following a 5-hour pneumonectomy for carcinoma of the left upper lobe in a 73-year old male patient. The massive embolization occurred 
during surgical manipulation and resulted in the patient's death three days later. Anaesthesia was not implicated.

\section{Discussion AND Conclusions}

Neuroleptanaesthesia, produced by the combination of diazepam-morphinenitrous oxide-curare, is an effective technique in the anaesthetic management of poor-risk patients undergoing major surgical procedures. Premedication with diazepam was essential and resulted in a marked degree of psychic sedation without significant depression of respiration and circulation.

Diazepam is safe and reliable when used intravenously as an induction agent but, as it does not produce sleep in one arm-brain circulation time ${ }^{15}$ the induction period is somewhat prolonged when compared to thiopentone. Diazepam is potent and, many times, for the induction of extremely poor-risk patients, only very small amounts (5-7.5 mg) were required. There was a marked decrease in laryngeal irritability, so that an oral airway was tolerated without coughing or laryngospasm. Although diazepam has a mild muscle relaxant action, there was no evident potentiation of the action of succinylcholine used for intubation; as for d-tubocurare, it was required in somewhat greater dosage than in conventional inhalation anaesthesia (mean dose $6 \mathrm{mg}$ in $30 \mathrm{~min}$ ). There are no reported toxic effects on the liver and kidney due to diazepam and, in this series, there was no aggravation of pre-existing hepatic or renal disease, even when the technique was used for repeat operations.

When compared to conventional neuroleptanaesthesia utilizing Innovar, this method demonstrated no decreased pulmonary compliance, no "lead-pipe" muscular rigidity, and no postoperative extrapyramidal excitation. In fact, this technique can be used safely in patients with Parkinson's disease, even those maintained on L-Dopa. Finally, there was no demonstrable potentiating effect of diazepam and morphine on the narcotic analgesics used postoperatively.

Hyperventilation with large tidal volumes and slow rates, maintained optimal arterial oxygen tensions during surgery, without the necessity for periodic hyperinflation to prevent the development of atelectasis. ${ }^{16}$ The associated hypocarbia, particularly during long surgical procedures, can result in alkalosis of the blood and spinal fluid, a depletion of body carbon dioxide stores, cerebral vasoconstriction, and may possibly contribute to postoperative apnea, hypoxia, ${ }^{1 \tau}$ and delayed reaction times. ${ }^{18}$

\section{SUMMARY}

Experience with 50 poor-risk surgical patients has been presented, in whom neuroleptanaesthesia was used. The drugs employed were diazepam and morphine supplemented with nitrous oxide, d-tubocurare, and hyperventilation. The induction period was prolonged up to 3-5 minutes, with remarkably stable cardiovascular function. There was a progressive decrease in respiration, so that assisted and controlled ventilation was utilized. The blood gas values showed adequate arterial oxygenation, and a mild respiratory alkalosis. Routine curare-reversal was carried out at the termination of anaesthesia, with rapid return of consciousness and orien- 
tation; tranquility, amnesia, and analgesia persisted well into the recovery period, making this pleasant for the patient.

It is recommended that in the poor-risk surgical patient, neuroleptanaesthesia with diazepam-morphine be administered with hyperventilation, but that provision be made to maintain normocarbia and normal acid-base balance.

\section{RÉSUMÉ}

On présente cinquante cas de mauvais risques chirurgicaux chez qui on a utilisé la neuroleptanesthésie. Les produits utilisés furent le diazépam et la morphine complétés par le protoxyde d'azote, la d-tubocurarine et l'hyperventilation. La période d'induction a duré de 3 à 5 minutes, sans trouble de la fonction cardiovasculaire. Il y a eu une diminution graduelle de la respiration, de sorte qu'on a utilisé la ventilation assistée ou contrôlée. L'analyse des gaz sanguins a montré une oxygénation artérielle suffisante et une légère alcalose respiratoire. A la fin de l'anesthésie on a pratiqué le renversement habituel du curare, ce qui a amené un retour rapide à la conscience et à l'orientation; le calme, l'amnésie et l'analgésie se sont prolongés durant la période de réveil, ce qui est très agréable pour le malade.

On recommande, pour les mauvais risques chirurgicaux, que la neuroleptanesthésie au diazépam-morphine soit administrée avec l'hyperventilation, mais qu'on ait la précaution de maintenir la normocarbie ct un équilibre acide-base normal.

\section{REFERENCES}

I. Dunnee, J. W. \& Haslett, W. H. K. The benzodiazepines. Brit. J. Anaesth., 42: 217 (1970).

2. Dalen, J. E.; Evans, G. L.; Banas, J. S.; Brooks, H. L.; Paraskos, J. A.; \& Dexter, L. The hemodynamic and respiratory effects of Diazepam (Valium $\mathbb{B}$ ). Anesthesiology, 30: $259(1969)$.

3. Tornetta, F. J. Diazepan as pre-anesthetic medication. Anesth. \& Analg., 44: 449 (1965).

4. Brandt, A. L. \& Oakes, F. D. Preanesthesia medication: double-blend study of a new drug, diazepam. Anesth. \& Analg., 44: 125 (1965).

5. McClish, A. Diazepam as an intravenous induction agent for general anaesthesia. Canad. Anaesth. Soc. J., 13: 562 (1966).

6. BAKER, A. B. Induction of anaesthesia with diazepam, Anaesthesia, 24:388 (1969).

7. KNapP, R. B. \& Dubow, H. Comparison of diazepam with thiopental as an induction agent in cardiopulmonary disease. Anesth. \& Analg., 49: 722 (1970).

8. WYant, G. M. \& Stundex, L. T. A study of diazepam (Valium ${ }^{\circledR}$ ) for induction of anaesthesia. Canad. Anaesth. Soc. J., 17: 166 (1970).

9. Richter, K. The combined use of valium and alloferin in neuroleptanalgesia. Anesth. \& Analg., Réanim. 23: 37l (1966).

10. Frumin, M. J.; Herekar, W.; \& Jakvik, M. E. The amnesic effects of diazepam and scopolamine in man. Intern. Congr. Pharmacol., 4th, Basle, 1969. p. 289.

11. Devine, J. W.; Haslett, W. H. K.; Keilty, S. R.; \& Pandit, S. K. Studies of drugs given before anaesthesia xx: Diazepam-containing mixtures. Brit. J. Anaesth., 42: 143 (1970).

12. Clatre, P. R. F.; Eccersley, P. S.; Frisby, J. P.; \& Thornton, J. A. The amnesic effect of diazepam (Valium). Brit. J. Anaesth., 42: 690 (1970).

13. Heller, M. L.; Watson, R. JR.; \& ImRedy, D. S. Effect of nitrous oxide uptake on arterial oxygenation. Anesthesiology, 28: 904 (1967).

14. Prys-Roberts, C.; Kelanax, C. R.; \& Greenbaum, R. The influence of circulatory factors in arterial oxygenation during anaesthesia in man. Anaesthesia, 22: 257 (1967).

15. Brown, S. S. \& DundeE, J. W. Clinical studies of induction agents xxv: Diazepam. Brit. J. Anaesth., 40: $108(1968)$. 
16. Bendixen, H. H.; Hedley-Whyte, J.; \& LAver, M. B. Impaired oxygenation in surgical patients during general anaesthesia with controlled ventilation. A concept of atelectasis. New Eng. J. Med., 269: 991 (1963).

17. Sullivan, S. F. \& Pattenson, E. W. Posthyperventilation hypoxia. Anesthesiology, 29: $981(1968)$.

18. Wollman, S. B. \& Orkin, L. R. Postoperative human reaction time and hypocarbia during anaesthesia. Brit. J. Anaesth., 40: 920 (1968). 